\title{
Investigate The Sintering Behavior of IZO Ceramic Targets Prepared By Pressure Slip Casting
}

Chaofei Liu

Zhengzhou University

Xueyun Zeng

Zhengzhou University

Xiaokai Liu

Zhengzhou University

Benshuang Sun

Zhengzhou University

Zhongheng Zuo

Zhengzhou University

Yongchun Shu

Zhengzhou University

Yang Liu ( $D$ louis@zzu.edu.cn )

Zhengzhou University https://orcid.org/0000-0001-6077-8912

Jianhong $Y i$

Kunming University of Science and Technology

Jilin He

Zhengzhou University

\section{Research Article}

Keywords: IZO, Slip casting, Sintering, Grain size

Posted Date: October 26th, 2021

DOI: https://doi.org/10.21203/rs.3.rs-968565/v1

License: (c) (1) This work is licensed under a Creative Commons Attribution 4.0 International License.

Read Full License 


\title{
Investigate the sintering behavior of IZO ceramic targets prepared by pressure slip casting
}

Chaofei Liu ${ }^{\mathrm{a}}$, Xueyun Zeng ${ }^{\mathrm{a}}$, Xiaokai Liu ${ }^{\mathrm{a}}$, Benshuang Sun ${ }^{\mathrm{a}}$, Zhongheng Zuo ${ }^{\mathrm{a}}$, Yongchun Shu ${ }^{\mathrm{a}}$, Yang Liu $^{\text {a*}}$, Jianhong $\mathrm{Yi}^{\mathrm{b}}$, Jilin $\mathrm{He}^{\mathrm{a}}$

aSchool of Materials Science and Engineering, Zhengzhou University, Zhengzhou 450001, China

${ }^{b}$ Faculty of Materials Science and Engineering, Kunming University of Science and Technology, Kunming, 650093, China

*Corresponding author: louis@zzu.edu.cn (Yang Liu)

\begin{abstract}
The density and phase structure uniformity of the IZO ceramic target would have an effect on the optoelectronic properties of the sputtered film. In this work, a uniformly dispersed IZO slurry was used to obtain high-density green IZO compacts by the slip casting process. Based on the grain size and shrinkage data of IZO ceramics, the densification process was investigated, while the apparent activation energy and growth activation energy were also calculated. The results of XPS showed that sintering in an oxygen atmosphere can increase the concentration of oxygen vacancies of IZO ceramic to improve its electrical properties. Finally, IZO ceramics with a grain size of 3-6 $\mu \mathrm{m}$ and resistivity of $1.5 \mathrm{~m} \Omega \cdot \mathrm{cm}$ were obtained by a twostep sintering method.
\end{abstract}

Keywords: IZO, Slip casting, Sintering, Grain size

\section{Introduction}

The continuous development of TCO (transparent conductive oxide) films in terms of electrical conductivity and optical transmittance performance has laid the foundation for promising applications in the semiconductor, flat panel display, solar cell, and energy-saving glass industries. The field of screen display, especially OLED, is leading the development trend of the flexible display market. Facing the innovative demand for flexible, bendable, and foldable display devices, a TCO film with a smooth surface, low stress, good thermal stability, and stable bonding to the substrate has been constantly developed[1,2]. In the indium oxidebased system, the doping element $\mathrm{Zn}$ can promote the amorphization of the film to obtain a TCO film with low surface roughness, low internal stress, and good etching performance[3]. Meanwhile, the visible light transmittance of the film can reach about $90 \%$ and possess certain thermal stability characteristics[4,5]. Several strengths are worth mentioning, indium zinc oxide (IZO) thin film can be deposited at near room temperature and its crystallization temperature greater than $600^{\circ} \mathrm{C}[6]$. These performance advantages indicate that IZO films have great potential for development.

So far, the properties and applications of IZO films have been made by several scholars. The sputtering parameters of IZO films were optimized to greatly improve the electrical conductivity $(1962 \pm 3.84 \mathrm{~S} / \mathrm{cm})$ and the surface roughness $(0.55 \pm 0.03 \mathrm{~nm})$, while severely reducing the residual internal stress $(-0.52 \pm 0.04 \mathrm{GPa})[7]$. All of the above demonstrates that IZO films can be used in next-generation OLED flexible devices. To decrease gate driver power consumption, Jun-Wei Chen[8] prepared a single-negative-source gate driver using IZO film. It consumes only $101 \mu \mathrm{W}$ per stage at a clock frequency of $66.7 \mathrm{kHz}$, which is much lower than that of a dual-negative-source gate driver. In a study, it has been confirmed the feasibility of 
IZO thin films in preparing non-volatile memory (NVM) devices [9]. The $\mathrm{IZO} / \mathrm{TiO}_{2}$ thin film devices with a $6: 4 \mathrm{In} / \mathrm{Zn}$ atomic ratio were fabricated. The research shows that the device has many superior properties, such as excellent stability, high content of oxygen vacancies (27.49\%), high switching current ratio $\left(>10^{3}\right)$, and ultra-low switching voltage (close to 0 ). Magnetron sputtering is a common process for preparing thin films. To improve the purity, denseness, and composition uniformity of thin films, sputtering targets need to have the characteristics of high purity, high density, multiple components, and uniform grains. The microstructure of the green body has a great influence on ceramic performance after sintering. The preparation process of the original powder determines its particle size and morphological structure[10]. Nanoparticles without agglomerated structure and uniform particle size can reduce the coordination number of micropores and be gradually eliminated during the sintering process, thus enhancing ceramic densities[11]. The pressure casting technique, unlike the traditional casting process, takes the dual action of external pressure and the capillary force (50 $-100 \mathrm{KPa})$ of the plaster mold itself to improve the density and performance of the green body[12, 13]. However, little research has been done on the process of preparing highperformance IZO ceramic targets.

In this study, the uniformly dispersed IZO slurry with high solid content and low viscosity were firstly prepared to produce a uniform density of green IZO compact by pressure slip casting. In addition, the densification behavior and grain growth mechanism of IZO ceramics are investigated in detail. Besides, the apparent activation energy required for densification and grain growth was calculated by constructing MSC models and the brook dynamic model. Finally, the two-step sintering method was used to optimize the densification process and control the grain size and second phase distribution, thereby obtaining IZO ceramics with high densification and excellent optoelectronic properties.

\section{Experimental}

\subsection{Sample Preparation}

High-purity indium oxide (99.99\%) and zinc oxide (99.99\%) powder were homogeneously mixed at a mass ratio of 89.3:10.7 to prepare IZO ceramics. Ammonium polyacrylate (dispersing agent) and polyvinyl alcohol (PVA, bonding agent) were added to the $\mathrm{In}_{2} \mathrm{O}_{3}-\mathrm{ZnO}$ mixed powders in a wet milling process with zirconia balls and deionized water. The solid content of the IZO slurry was $75 \mathrm{wt} . \%$ and the ball milling time was generally controlled at 24-48 $\mathrm{h}$. The ball-to-powder mass ratio is $1: 1$, and the rotation speed is $250 \mathrm{r} / \mathrm{min}$. Followed by that, uniformly dispersed IZO slurry was poured into the plaster mold via an external pressure (0.1-0.5 MPa) after vacuum-treated for de-airing. To increase the packing density of the IZO slurry, the pressure duration is often set to about $6 \mathrm{~h}$. After demolding, the green IZO compacts were dried at a constant temperature $\left(30^{\circ} \mathrm{C}\right)$ with high relative humidity $(80 \%)$ for $48 \mathrm{~h}$ to ensure a slow drying rate. Finally, the green IZO compacts with a relative density of $60 \pm 1 \%$ were obtained. In the convenient sintering process, the green IZO compacts were heated at a heat rate of $1^{\circ} \mathrm{C} / \mathrm{min}$ to $750^{\circ} \mathrm{C}$ soaking $10 \mathrm{~h}$ for removing the organic residues, and then the sintering temperature was increased at a rate of $3{ }^{\circ} \mathrm{C} / \mathrm{min}$ to $1400^{\circ} \mathrm{C}, 1500^{\circ} \mathrm{C}$ for $20 \mathrm{~h}$. At the same time, a two-step sintering process was applied to the sintering of IZO ceramics, samples were first heated to a higher temperature $\mathrm{T}_{1}\left(1400-1600^{\circ} \mathrm{C}\right)$, then cooled to $\mathrm{T}_{2}(1350$ $1500^{\circ} \mathrm{C}$ ) at $10{ }^{\circ} \mathrm{C} / \mathrm{min}$ for $20-30 \mathrm{~h}$. 


\subsection{Characterization}

A digital rotational viscometer (DV2TLV, USA) was adopted to perform the rheological properties of the IZO slurry. Measurement and analysis of the particle size distribution of IZO slurry through Granulometric Analysis (NanoPlus HD, American). The thermal dilatometer (PCY-1600, China) was utilized to record the densification behavior of green IZO compacts at different heating rates. The size of the green IZO compacts was set at $40 \times 10 \mathrm{~mm}$ to facilitate accurate data. At the same time, the master sintering curve (MSC) was further studied for predicting the densification behavior and calculating the activation energy of IZO ceramics. $\mathrm{Cu}$ $\mathrm{K} \alpha$ radiation was applied by X-ray diffraction (XRD, Empyrean, Netherlands) mode to investigate the phase composition of the IZO targets. For each sample under different sintering processes, the morphologies of IZO ceramics were visualized by scanning electron microscopy (SEM, Quanta $250 \mathrm{FEG}, \mathrm{USA}$ ) after polishing and thermal etching at $1000^{\circ} \mathrm{C}$ for $1 \mathrm{~h}$. Research on the elemental chemical states of In, Zn, and O in IZO ceramics was inspected by X-ray photoelectron spectroscopy (XPS, AXIS Supra, Japan). Electronic probes (EPMA, EPMA1720, Japan) were used to analyze and quantify the elements of In, Zn, and O in micro-regional. Based on the Archimedes method, the density of IZO ceramics was calculated precisely and the resistivity of IZO ceramics was measured by four-probes (RTS-8, China).

\section{Results and discussion}

\subsection{The rheological properties and particle size distribution of the IZO slurry}

The powder needs to be pretreated to improve the rheological properties of the slurry, thus ensuring a uniform particle distribution and no agglomeration in the green compact. To ensure the stability of the particles in the slurry, $1.8 \mathrm{wt} . \% \mathrm{NH}_{4} \mathrm{PAA}$ was added to improve the dispersion effect[14]. The viscosity curves and shear stress curves (Fig. 1) illustrated the variation of the rheological properties of the slurry with the ball milling time. It can be seen the apparent viscosity value of the slurry with a ball milling time for $40 \mathrm{~h}$ is $45 \mathrm{mPa} \cdot \mathrm{s}$ from $20 \mathrm{~s}^{-1}$ to $80 \mathrm{~s}^{-1}$, which is slightly lower than that of $32 \mathrm{~h}$ and $48 \mathrm{~h}$. Other than that, the suspensions with a ball milling time of $40 \mathrm{~h}$ showed a lower yield shear stress. The data indicates that $40 \mathrm{~h}$ ball milling time is the most suitable slurry for pressure slip casting.
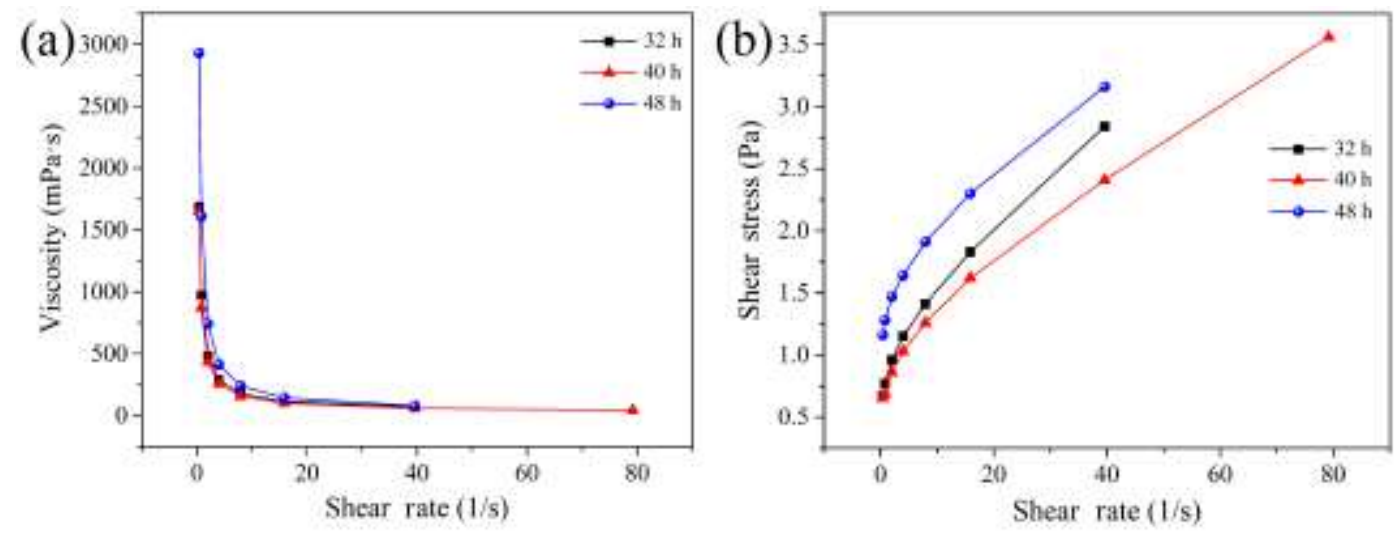

Fig. 1. Variation of rheological properties of IZO slurry with ball milling time: (a) Viscosity-Shear rate,

(b) Shear stress-Shear rate.

However, it is not enough to rely on the rheological properties of the slurry alone for the performance of the green IZO compacts, but also to consider the degree of dispersion of 
agglomerated particles as an important parameter. The nanoparticle size distribution of the IZO slurry was also examined while sampling at different ball milling times. Fig. 2 depicts the relationship between different ball milling times and particle size distribution. It verifies that with the increase of ball milling time, the slurry D50 particle size firstly decreases from 510 $\mathrm{nm}$ to $365 \mathrm{~nm}$ and then slightly increases to $386 \mathrm{~nm}$. As the agglomeration phenomenon weakens, the total surface area of uniformly dispersed nanoparticles increases, generating large surface energy, and the interparticle attraction increases again, which leads to the reagglomeration of particles. As a result, the slurry with $40 \mathrm{~h}$ ball milling time has the best rheological properties and smaller nanoparticle size distribution, so it will be selected to prepare the green IZO compact.
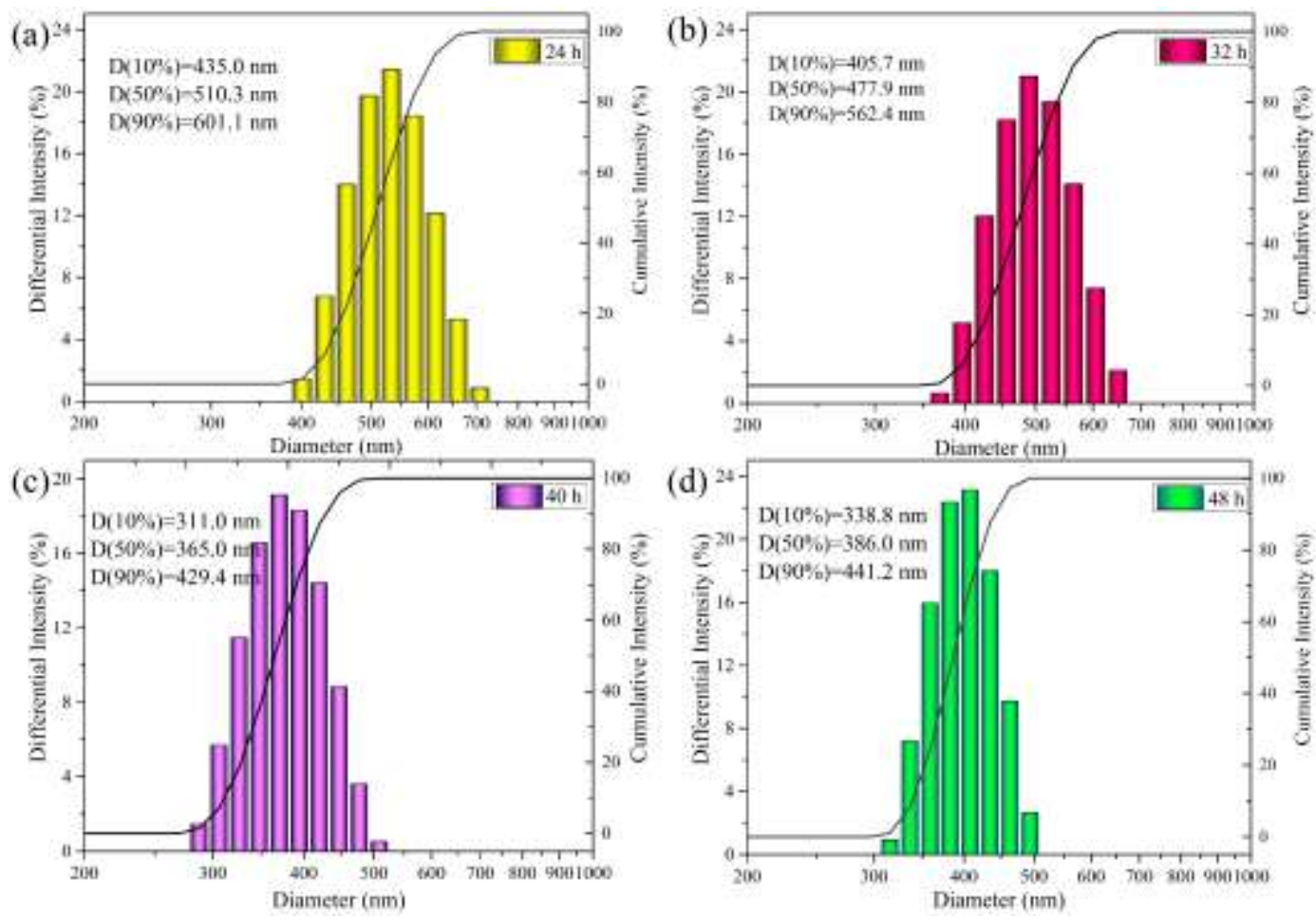

Fig. 2. The nanoparticle size distribution of IZO slurry with different ball milling times: (a) $24 \mathrm{~h}$, (b) $32 \mathrm{~h}$, (c) $40 \mathrm{~h}$, (d) $48 \mathrm{~h}$.

\subsection{Densification behavior of IZO ceramics and calculation of activation energy based on constructing MSC.}

The shrinkage behavior of green IZO compacts in the temperature range of $0-1500^{\circ} \mathrm{C}$ was recorded using a thermal dilatometer. As shown in Fig. 3, the effect of different heating rates $\left(3,5\right.$, and $\left.7{ }^{\circ} \mathrm{C} / \mathrm{min}\right)$ on the degree of densification is compared. It is obvious that when the heating rate is $3{ }^{\circ} \mathrm{C} / \mathrm{min}$, the shrinkage is $16.1 \%$, which is higher than others. From the shrinkage rate curves of the three samples, there are two large peaks around $1080^{\circ} \mathrm{C}(0.11,0.19$, $0.27 \% / \mathrm{min}$, respectively) and $1305^{\circ} \mathrm{C}(0.11,0.17,0.23 \% / \mathrm{min}$, respectively), and the trend of the three curves is consistent. For the densification behavior in Fig.3, the sintering process was divided into three periods based on factors such as reduced porosity, decreased surface energy, and grain growth: Pre-sintering, Mid-sintering, and After-sintering. The initial stage of sintering (Fig.3 a-I) is mainly characterized by the formation and growth of interparticle necks, and the shrinkage of green IZO compact at this stage is about $5 \%$, corresponding to a temperature range 
of $900-1050^{\circ} \mathrm{C}$. The next stage (Fig. 3 a-II) is the period of rapid grain growth, intergranular pores migrate and eventually transform into a closed state. At the later stage (Fig.3 a-III) of sintering, the closed pores continue to decrease and nearly spherical pores appear at the triple junction, and the relative density reaches more than $95 \%$.
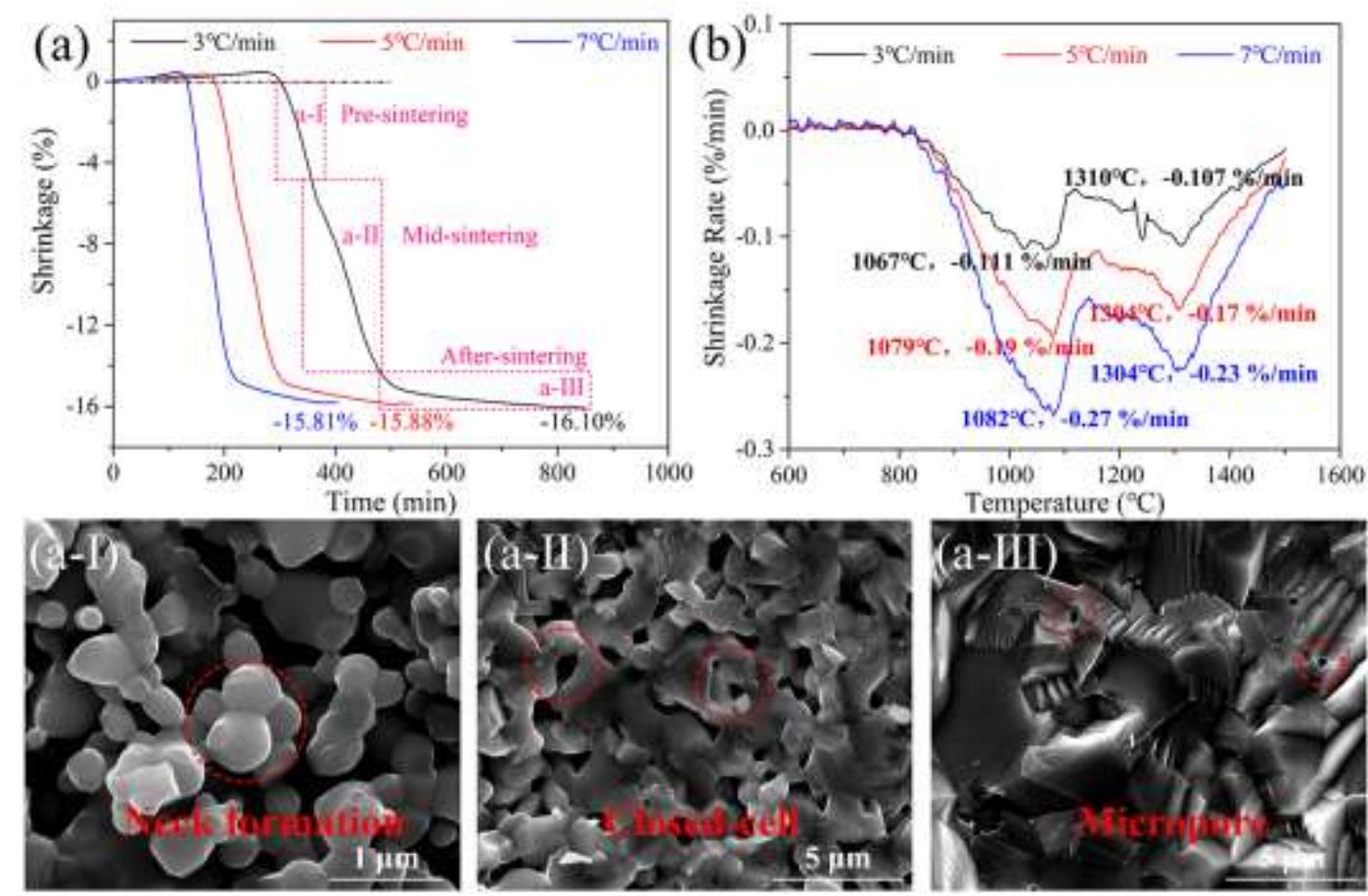

Fig. 3. Sintering densification process of the green IZO compacts at different heating rates: (a) Variation of shrinkage with time (a-I, a-II, a-III are the fracture profiles of three sintering periods), (b) Curvature of shrinkage rate with temperature.

Dilatometric shrinkage data not only monitor the densification process of the samples but also predict the final density of the ceramics and calculate the apparent activation energy. Johnson constructed a master sintering curve theory (MSC) for pressureless sintering by utilizing a full-term sintering model[15]. The model of MSC starts from the densification rate equation, which is derived as follows:

$$
-\frac{d L}{L d t}=\frac{\gamma \Omega}{k T}\left(\frac{\Gamma_{v} D_{v}}{G^{3}}+\frac{\Gamma_{b} \delta D_{b}}{G^{4}}\right)
$$

Eq. 1 is the instantaneous linear shrinkage in the sintering process, where $\mathrm{L}$ is the length of the sample, $t$ is the time, $\mathrm{T}$ is the temperature. $\gamma$ is the surface energy, $\Omega$ is the atomic volume, $\mathrm{k}$ is the Boltzmann constant, $\mathrm{G}$ is the grain size, $\delta$ is the grain boundary width; The value of $\Gamma$ is related to the driving force, the average diffusion distance and the mean grain size of different sintering rate; $D_{b}$ and $D_{v}$ are the grain boundary diffusion coefficient and volume diffusion coefficient, respectively. In the case of isotropic sintering, the linear shrinkage rate can be transformed into the densification rate according to Eq. 2 .

$$
-\frac{\mathrm{dL}}{\mathrm{Ldt}}=\frac{\mathrm{d} \rho}{3 \rho d t}
$$

where $\rho$ is the relative density. Assuming that there is only one diffusion mechanism (grain boundary diffusion or volume diffusion) in the sintering process. By simplifying Eq. 1 and Eq. 
2 and substituting the diffusion coefficient formula, it can obtain

$$
\frac{k}{\gamma \Omega \delta D_{0}} \int_{\rho_{0}}^{\rho} \frac{(G(\rho))^{n}}{3 \rho \Gamma(\rho)} d \rho=\int_{0}^{t} \frac{1}{T} \exp \left(-\frac{Q}{R T}\right) d t
$$

Here, if $\Gamma(\rho)$ and $G(\rho)$ are functions of only density and the sintering kinetic influence on the structural evolution during the sintering process is denoted by $\Phi(\rho)$, the left of Eq. 3 can become

$$
\Phi(\rho)=\frac{k}{\gamma \Omega \delta D_{0}} \int_{\rho_{0}}^{\rho} \frac{(G(\rho))^{n}}{3 \rho \Gamma(\rho)} d \rho
$$

The right of Eq. 3 is related to the atomic diffusion process. The function only depends on variables such as $\mathrm{t}, \mathrm{T}, \mathrm{Q}$.

$$
\Theta(t, T(t)) \equiv \int_{0}^{t} \frac{1}{T} \exp \left(-\frac{Q}{R T}\right) d t
$$

Consequently, Eq.3 becomes

$$
\Phi(\rho)=\Theta(t, T(t))
$$

The main sintering curve (MSC) can be defined by a functional relationship between $\Phi(\rho)$ and $\rho$. Since the derivation process requires extensive numerical calculations, V. Pouchly et al. designed software to simplify the solution process of Q[16]. The curve of IZO ceramics about MSC can be obtained from the shrinkage data of three different heating rates, as shown in Fig. 4. The Mean Perpendicular Curve Distance (MPCD) in the inset is a standard statistical method to determine the overlap of the MSC curves, enabling more accurate Q values to be obtained. The data show that the curves with different heating rates have good overlap, to get precise apparent activation energy $\mathrm{Q}_{\mathrm{d}}=580 \mathrm{~kJ} / \mathrm{mol}$ ). The calculation of the grain growth activation energy in the next section can provide theoretical support for the subsequent two-step sintering process.

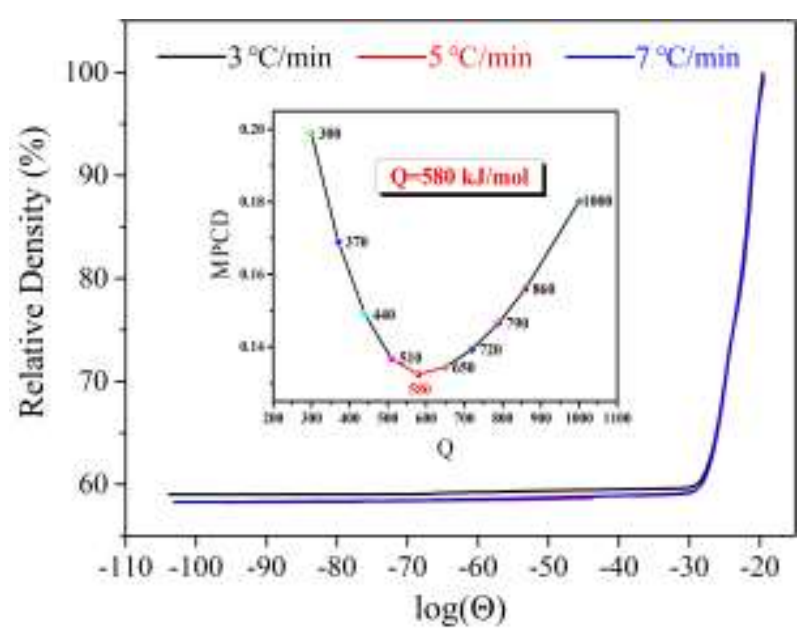


Fig. 4. Construct MSC and MPCD to calculate the activation energy of IZO ceramic.

\subsection{Calculation of the grain growth activation energy for IZO ceramics}

To analyze the grain growth mechanism of IZO ceramics, the grain sizes were counted at different sintering temperatures and holding times. Brook dynamic model can be used to evaluate the activation energy of grain growth for different atomic regimes[17, 18], as expressed in Eq. (7),

$$
G_{t}^{n}-G_{0}^{n}=k t
$$

Where $\mathrm{n}$ is the grain-growth exponent, $\mathrm{k}$ is the grain growth rate constant, $\mathrm{t}$ is the sintering time, $G_{t}$ and $G_{0}$ are the grain sizes at sintering times $t$ and 0 , respectively. Since the particle size of the original powder is so small and negligible, the Eq. 7 becomes

$$
G_{t}^{n}=k t
$$

Then take the logarithm of both ends of Eq. 8,

$$
\operatorname{In} G_{t}=\frac{1}{n} \operatorname{In} t+\frac{\ln k}{n}
$$

Eq. 9 is shown as a function of grain size and sintering time, where $\mathrm{n}$ is the inverse of the slope of the function. Fig. 5 contains the grain size statistics of IZO ceramics held at $1500^{\circ} \mathrm{C}$ for $0.5 \mathrm{~h}, 10 \mathrm{~h}, 20 \mathrm{~h}$, respectively. With the extension of holding time, the grain grows continuously from $2.73 \mu \mathrm{m}$ to $5.28 \mu \mathrm{m}$. According to the linear position, it can get $\mathrm{n}=6.52$ and $\mathrm{k}=5.37 \times 10^{20}$, as in Fig. 6 .

The value of $\mathrm{k}$ can be elaborated in further detail using the Arrhenius formula, then Eq. 8 can be expressed as

$$
G_{t}^{n}=k_{0} t \exp \left(-\frac{Q}{R T}\right)
$$

Substituting the previously found value of n, Eq. 10 can become

$$
6.52 \operatorname{In} G_{t}=-\frac{Q}{R T}+\left(\operatorname{In} k_{0}+\operatorname{In} t\right)
$$

Eq. 11 can be considered as a function of grain size and sintering temperature, where $-\mathrm{Q} / \mathrm{R}$ is the slope of the line. The IZO compacts were sintered at $1300^{\circ} \mathrm{C}, 1400^{\circ} \mathrm{C}, 1500^{\circ} \mathrm{C}$, and $1600^{\circ} \mathrm{C}$ for $10 \mathrm{~h}$ with grain sizes of $2.35 \mu \mathrm{m}, 2.71 \mu \mathrm{m}, 3.90 \mu \mathrm{m}$, and $7.50 \mu \mathrm{m}$, respectively, as shown in Fig. 7. The grain growth activation energy $\mathrm{Q}_{\mathrm{g}}=690 \mathrm{~kJ} / \mathrm{mol}$ is from processing data in Fig. 8. Consequently, the apparent activation energy $(580 \mathrm{~kJ} / \mathrm{mol})$ calculated by MSC is less than the grain growth activation energy, which can prove the rational implementation of twostep sintering. 

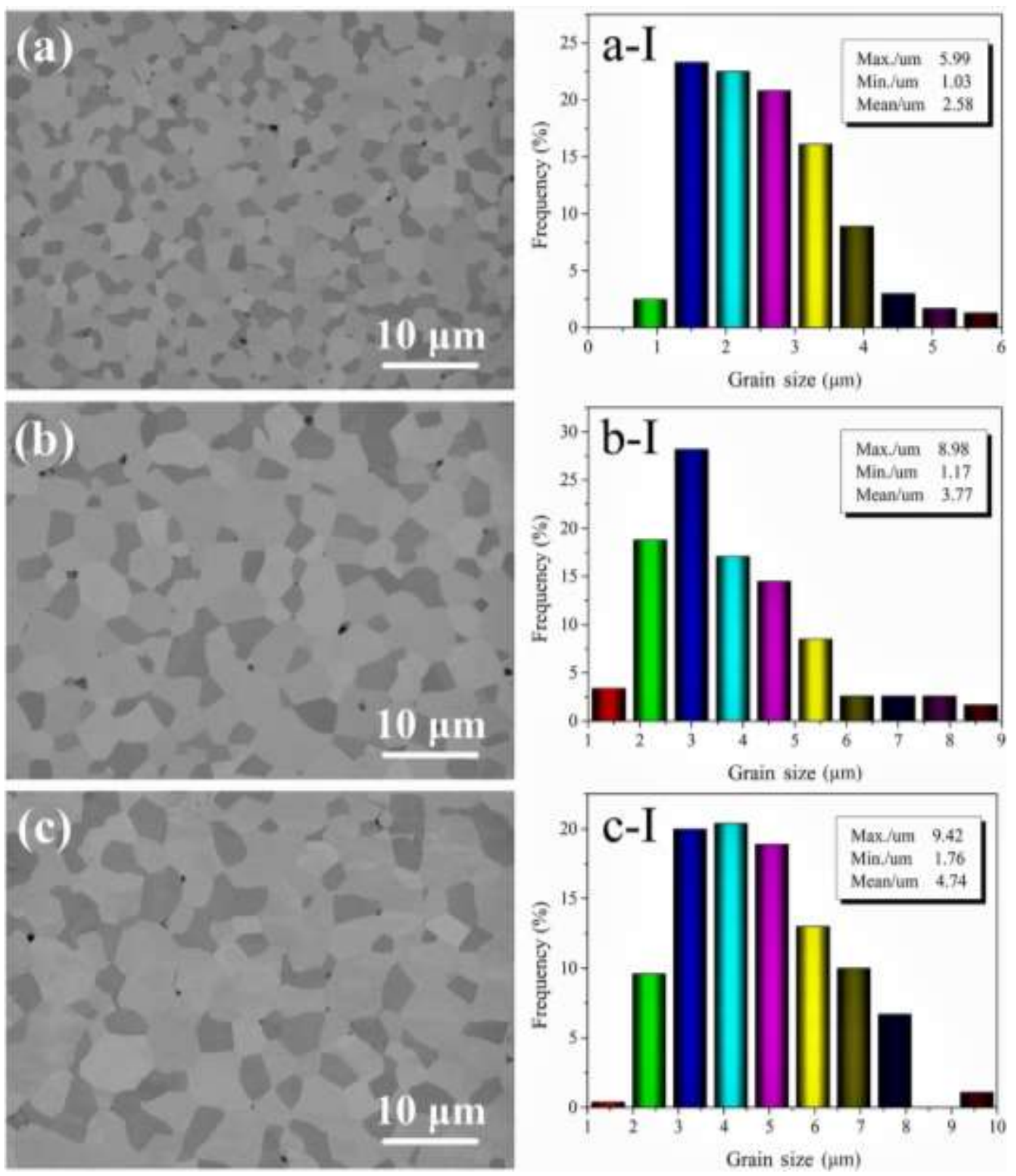

Fig. 5. Grain size distribution and morphology of IZO ceramics sintered at $1500^{\circ} \mathrm{C}$ : (a) $0.5 \mathrm{~h}$, (b) $10 \mathrm{~h}$, (c) $20 \mathrm{~h}$.

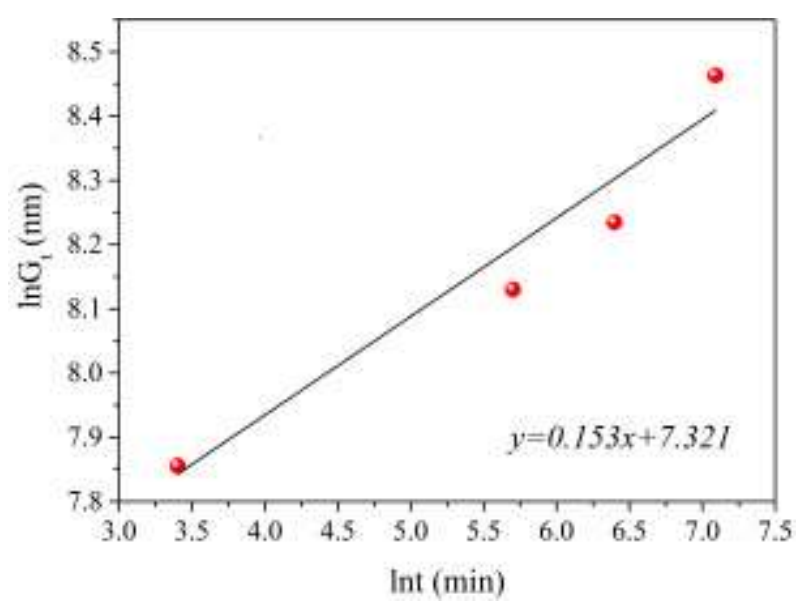


Fig. 6. Linear plot of $\operatorname{InG}_{\mathrm{t}}$ versus Int for IZO ceramic.
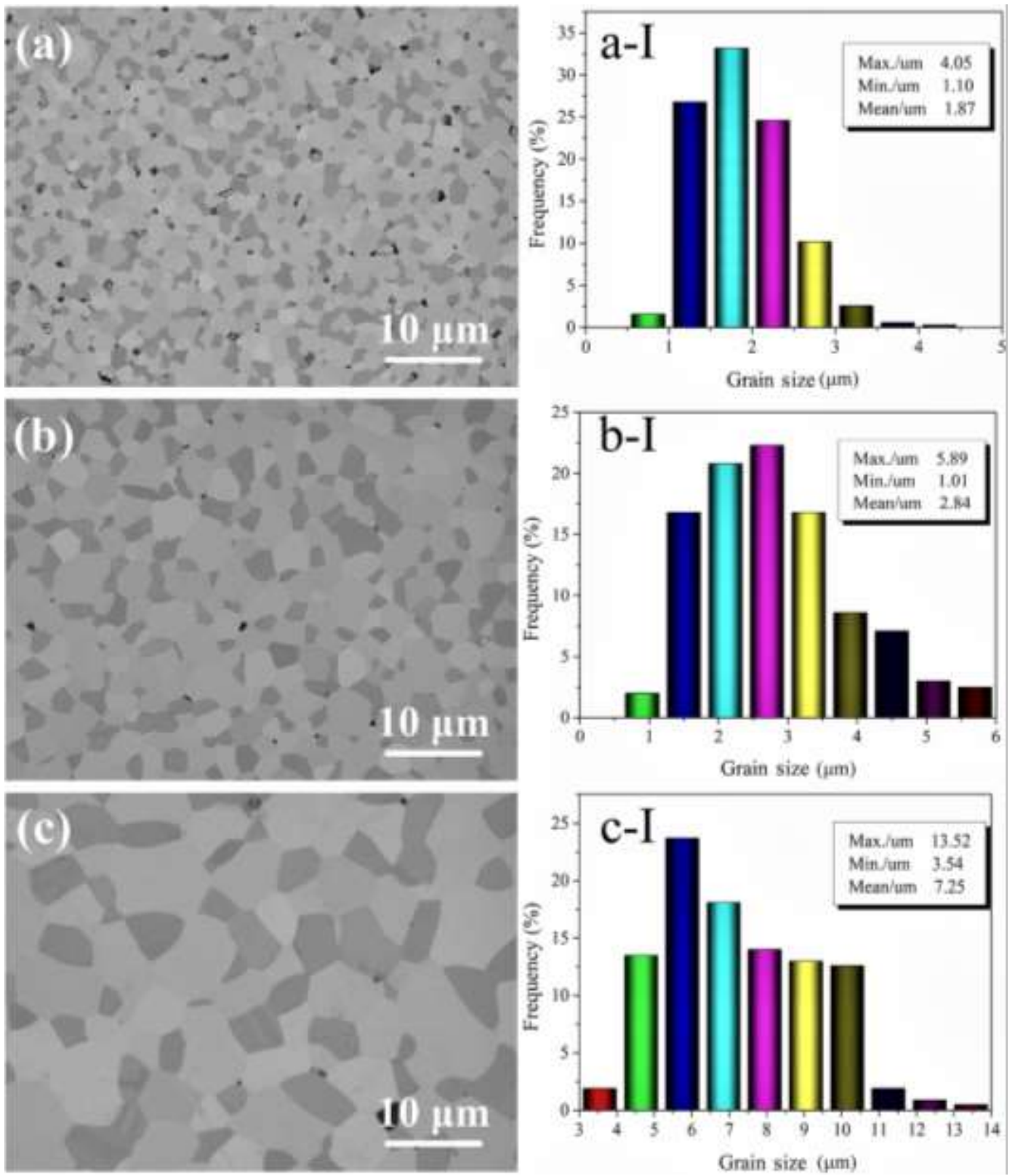

Fig. 7. Grain size distribution and morphology of IZO ceramics: (a) $1300^{\circ} \mathrm{C}$, (b) $1400^{\circ} \mathrm{C}$, (c) $1600^{\circ} \mathrm{C}$. 


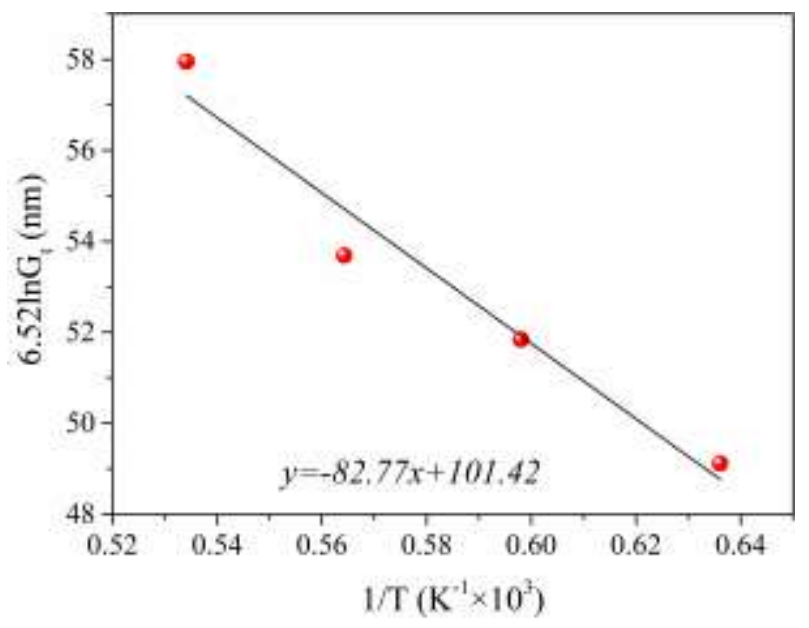

Fig. 8. Linear plot of $6.52 \mathrm{InG}_{\mathrm{t}}$ versus $1 / \mathrm{T}$ for IZO ceramics.

\subsection{Control the grain size of IZO ceramic targets by two-step sintering method}

The conventional sintering process has the problem of not being able to separate the densification and grain growth processes of ceramics. Although IZO ceramic targets can be completely densified, the grains also grow rapidly in the late sintering stage, showing a gradual coarsening phenomenon. Fortunately, the two-step sintering method was proposed by wang et al[19]. The temperature is first increased to a higher temperature $T_{1}$ to induce rapid densification of the ceramic, and then cooled down to $T_{2}$ and held for a long time. Holding at lower temperatures can inhibit grain boundary migration and avoid abnormal grain growth. Therefore, this section will explore the optimal $\mathrm{T}_{1} \& \mathrm{~T}_{2}$ combination application and the twostep sintering process parameters are listed in Table 1.

Table 1 . Sintering process condition and density of IZO ceramics.

\begin{tabular}{ccccccc}
\hline Sample & $\mathrm{T}_{1}\left({ }^{\circ} \mathrm{C}\right)$ & $\mathrm{t}_{1}(\mathrm{~h})$ & $\mathrm{T}_{2}\left({ }^{\circ} \mathrm{C}\right)$ & $\mathrm{t}_{2}(\mathrm{~h})$ & $\rho_{\text {relative }}(\%)$ & Mean grain size $(\mu \mathrm{m})$ \\
\hline CS1 & 1300 & 10 & - & - & 95.9 & 1.9 \\
CS2 & 1400 & 10 & - & - & 98.7 & 2.8 \\
CS3 & 1500 & 0.5 & - & - & 98.9 & 2.6 \\
CS4 & 1500 & 10 & - & - & 99.0 & 3.8 \\
CS5 & 1500 & 20 & - & - & 98.9 & 4.7 \\
CS6 & 1600 & 10 & - & - & 98.1 & 7.3 \\
TSS1 & 1450 & 0 & 1300 & 20 & 97.9 & 2.3 \\
TSS2 & 1450 & 0 & 1350 & 20 & 98.6 & 2.6 \\
TSS3 & 1450 & 0 & 1400 & 20 & 98.8 & 2.9 \\
TSS4 & 1500 & 0 & 1300 & 20 & 98.8 & 2.9 \\
TSS5 & 1500 & 0 & 1350 & 20 & 98.9 & 3.0 \\
TSS6 & 1500 & 0 & 1400 & 20 & 99.5 & 3.1 \\
TSS7 & 1500 & 0 & 1400 & 30 & 99.2 & 3.9 \\
TSS8 & 1550 & 0 & 1400 & 20 & 99.1 & 4.7 \\
TSS9 & 1600 & 0 & 1450 & 20 & 99.2 & 6.3 \\
\hline
\end{tabular}


Fig. 9 shows the variation pattern of grain distribution with adjusting $T_{1}$ and $T_{2}$. It is known that the $1400-1600^{\circ} \mathrm{C}$ is the rapid grain growth stage from the conventional sintering process. The mean grain size of CS1 was only $1.9 \mu \mathrm{m}$, so the starting temperature of $\mathrm{T}_{2}$ was set to $1300^{\circ} \mathrm{C}$ and incremented by $50^{\circ} \mathrm{C}$ to obtain high-density IZO ceramics with smaller grains. When the sintering temperature $T_{2}$ increased, the aggregation of small particles was gradually eliminated and the porosity of IZO ceramics decreased significantly. By adjusting $\mathrm{T}_{1}$ and $\mathrm{T}_{2}$ properly, the relative density of TSS 6 increased from $97.9 \%$ to $99.5 \%$, while the average grain size of IZO ceramics changed from 2.3 to $3.1 \mu \mathrm{m}$ without excessive grain growth. Therefore, the grain size is effectively controlled by the TSS method in the densification process of IZO ceramics.
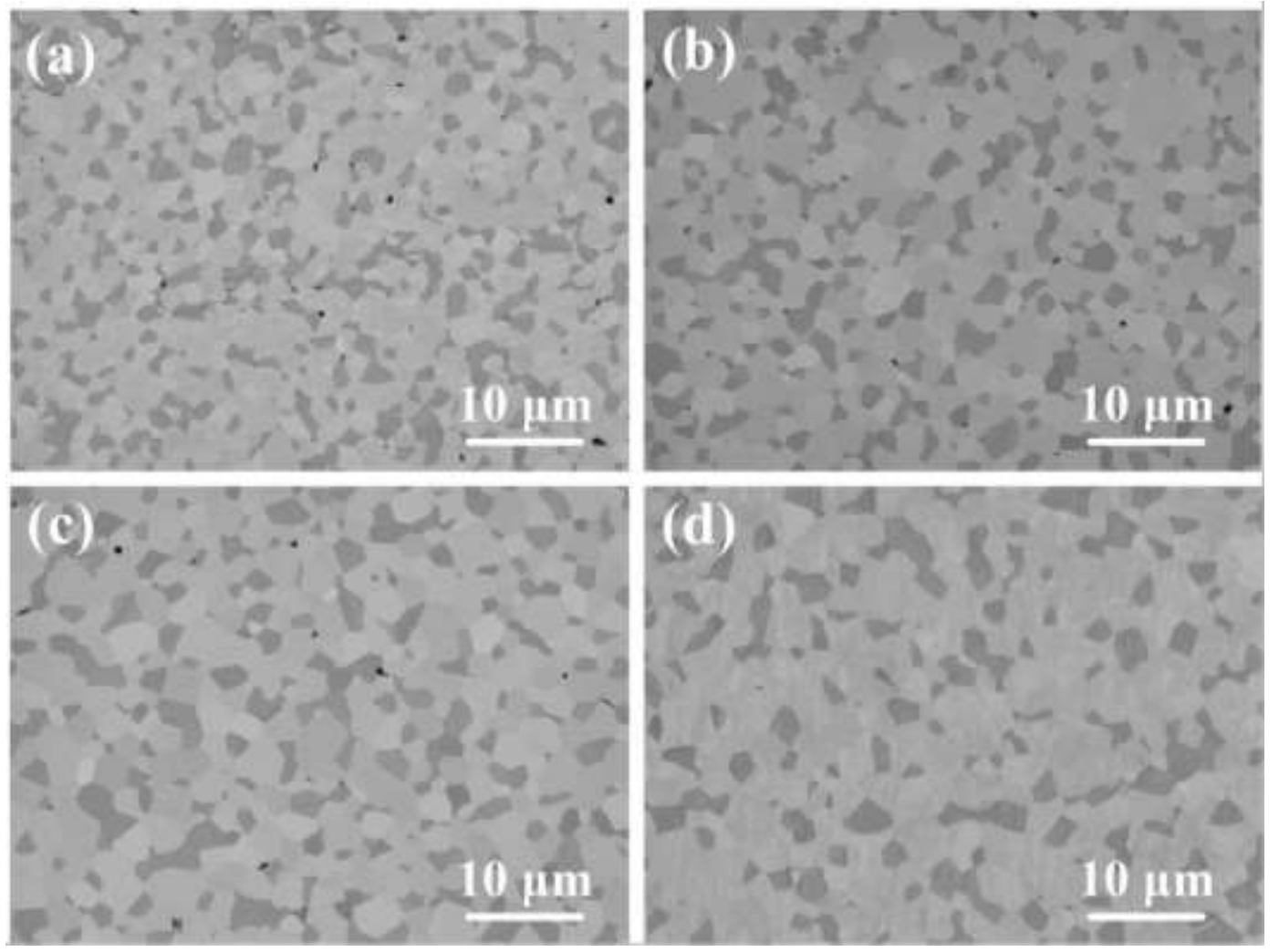

Fig. 9. Grain microstructure of IZO ceramics sintered by the two-step sintering method: (a) $\mathrm{T}_{1}=1450^{\circ} \mathrm{C}$, $\mathrm{T}_{2}=1300^{\circ} \mathrm{C}$; (b) $\mathrm{T}_{1}=1500^{\circ} \mathrm{C}, \mathrm{T}_{2}=1300^{\circ} \mathrm{C}$; (c) $\mathrm{T}_{1}=1500^{\circ} \mathrm{C}, \mathrm{T}_{2}=1350^{\circ} \mathrm{C}$; (d) $\mathrm{T}_{1}=1500^{\circ} \mathrm{C}, \mathrm{T}_{2}=1400^{\circ} \mathrm{C}$.

Further, the effect of increasing the holding time and sintering temperature on grain growth of IZO ceramics was investigated, as shown in Fig. 10. The average grain size of TSS 7, TSS 8 , TSS 9 is $3.89 \mu \mathrm{m}, 4.68 \mu \mathrm{m}$, and $6.28 \mu \mathrm{m}$, respectively. The increasing the holding time and sintering temperature induce the grain growth to continue and, at the same time, lead to a decrease in IZO ceramics density due to the volatilization of $\mathrm{Zn}$ elements at high temperatures. Sintering at high temperatures causes larger pores between grains, which increases the grain boundary potential and decreases the electron mobility, and thus increases the resistivity of IZO ceramics. Grain size, relative density, and resistivity changes of IZO ceramics are shown in Fig. 11. The sintering process of TSS 6 is optimal, where the relative density of IZO ceramic is $99.5 \%$, the average grain size is about $3 \mu \mathrm{m}$, and the resistivity is $1.5 \mathrm{~m} \Omega \cdot \mathrm{cm}$. When the $\mathrm{T}_{1}>$ $1500^{\circ} \mathrm{C}$ will cause rapid grain growth, $\mathrm{Zn}$ element volatilization and lead to the reduction of density so that the ceramic electrical properties deteriorate. 


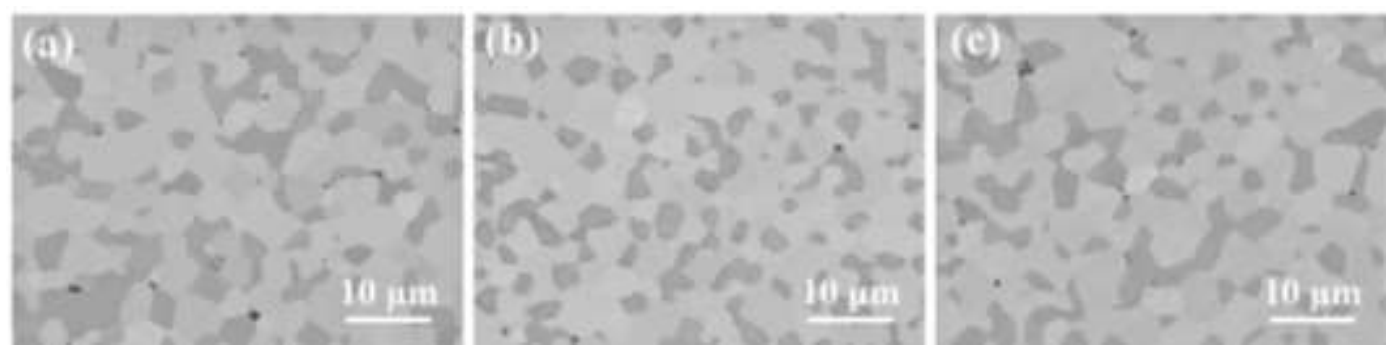

Fig. 10. Grain microstructure of IZO ceramics with TSS method: (a) $\mathrm{T}_{1}=1500^{\circ} \mathrm{C}, \mathrm{T}_{2}=1400^{\circ} \mathrm{C}, \mathrm{t}=30 \mathrm{~h}$; (b) $\mathrm{T}_{1}=1550^{\circ} \mathrm{C}, \mathrm{T}_{2}=1400^{\circ} \mathrm{C}, \mathrm{t}=20 \mathrm{~h} ;(\mathrm{c}) \mathrm{T}_{1}=1600^{\circ} \mathrm{C}, \mathrm{T}_{2}=1450^{\circ} \mathrm{C}, \mathrm{t}=20 \mathrm{~h}$.

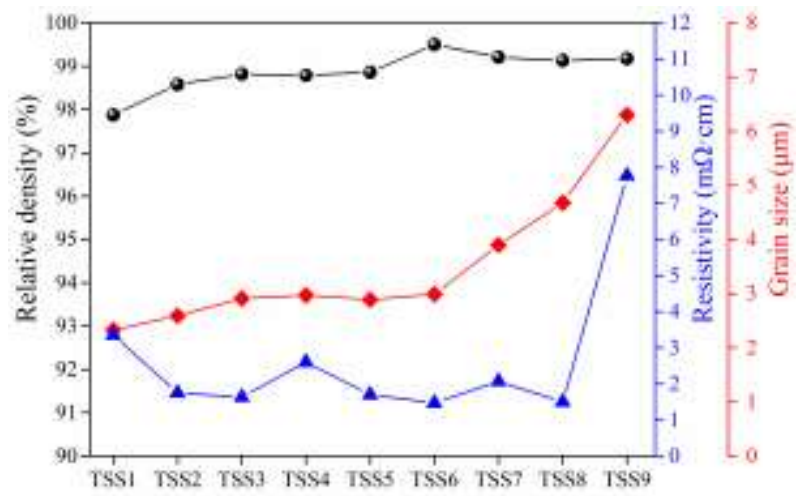

Fig. 11. Grain size, relative density, and resistivity of IZO ceramics sintered by the TSS method.

\subsection{Chemical state analysis and elemental distribution of IZO ceramics}

The XPS was used to detect the chemical state of IZO ceramics, narrow-spectrum analysis of In $3 \mathrm{~d}, \mathrm{Zn} 2 \mathrm{p}$, and O1s is given in Fig. 12 (b-d). The valence content of the elements is shown in Table 2. The indium peak can be split to fit into 2 valence states with binding energy positions at $\operatorname{In} 3 \mathrm{~d}_{5 / 2}{ }^{\mathrm{I}}(443.8 \mathrm{eV})$ and $\operatorname{In} 3 \mathrm{~d}_{5 / 2}{ }^{\mathrm{II}}(444.5 \mathrm{eV}) . \operatorname{In} 3 \mathrm{~d}_{5 / 2}{ }^{\mathrm{I}}, \operatorname{In} 3 \mathrm{~d}_{5 / 2}{ }^{\mathrm{II}}$ are oxygen deficiency $\operatorname{In}_{2} \mathrm{O}_{3-\mathrm{x}}$ state and $\mathrm{In}_{2} \mathrm{O}_{3}$ state $[6,20]$, respectively. The $\mathrm{In}_{2} \mathrm{O}_{3-\mathrm{x}}$ state of green IZO compacts after sintering rises significantly and is more abundant under an oxygen atmosphere $(89.58 \%)$. The $\mathrm{Zn} 2 \mathrm{p}$ peak was fitted with another component $\mathrm{Zn} 2 \mathrm{p}_{3 / 2}$, , which could be attributed to metallic $\mathrm{Zn}$ (1021.5 $\mathrm{eV}$ )[21]. The change in the position of the $\mathrm{Zn} 2 \mathrm{p}$ peak for the three specimens was almost negligible, and the valence state of $\mathrm{Zn}$ was more stable[22]. There are 3 states of oxygen present in IZO ceramics centered at $\mathrm{O}_{1} \mathrm{~s}^{\mathrm{I}}(529.3 \mathrm{eV}), \mathrm{O} 1 \mathrm{~s}^{\mathrm{II}}(531.3 \mathrm{eV})$, and $\mathrm{O} 1 \mathrm{~s}^{\mathrm{III}}(533.1 \mathrm{eV})$. The binding energy at $529.3 \mathrm{eV}$ would be owing to the bond of In-Zn-O. O1s ${ }^{\mathrm{II}}(531.3 \mathrm{eV})$ can be attributed to the oxygen vacancies and $\mathrm{O} 1 \mathrm{~s}^{\mathrm{III}}(533.1 \mathrm{eV})$ is caused by adsorbed oxygen[9, 23, 24]. The variation of oxygen vacancy content $\mathrm{O} 1 \mathrm{~s}^{\mathrm{II}}$ in sintering under different atmospheres follows the same trend as $\operatorname{In} 3 \mathrm{~d}_{5 / 2}$. The oxygen vacancy content was highest under oxygen sintering with a value of $72.66 \%$. The escape of oxygen from the crystal structure occupying the oxygen site anion generates a double ionization vacancy and two free electron carriers, and electrons are released from the oxygen vacancy, leading to an increase in mobility and free carrier concentration. Therefore, sintering in an oxygen atmosphere can increase the oxygen vacancy content and further improve the electrical conductivity. 

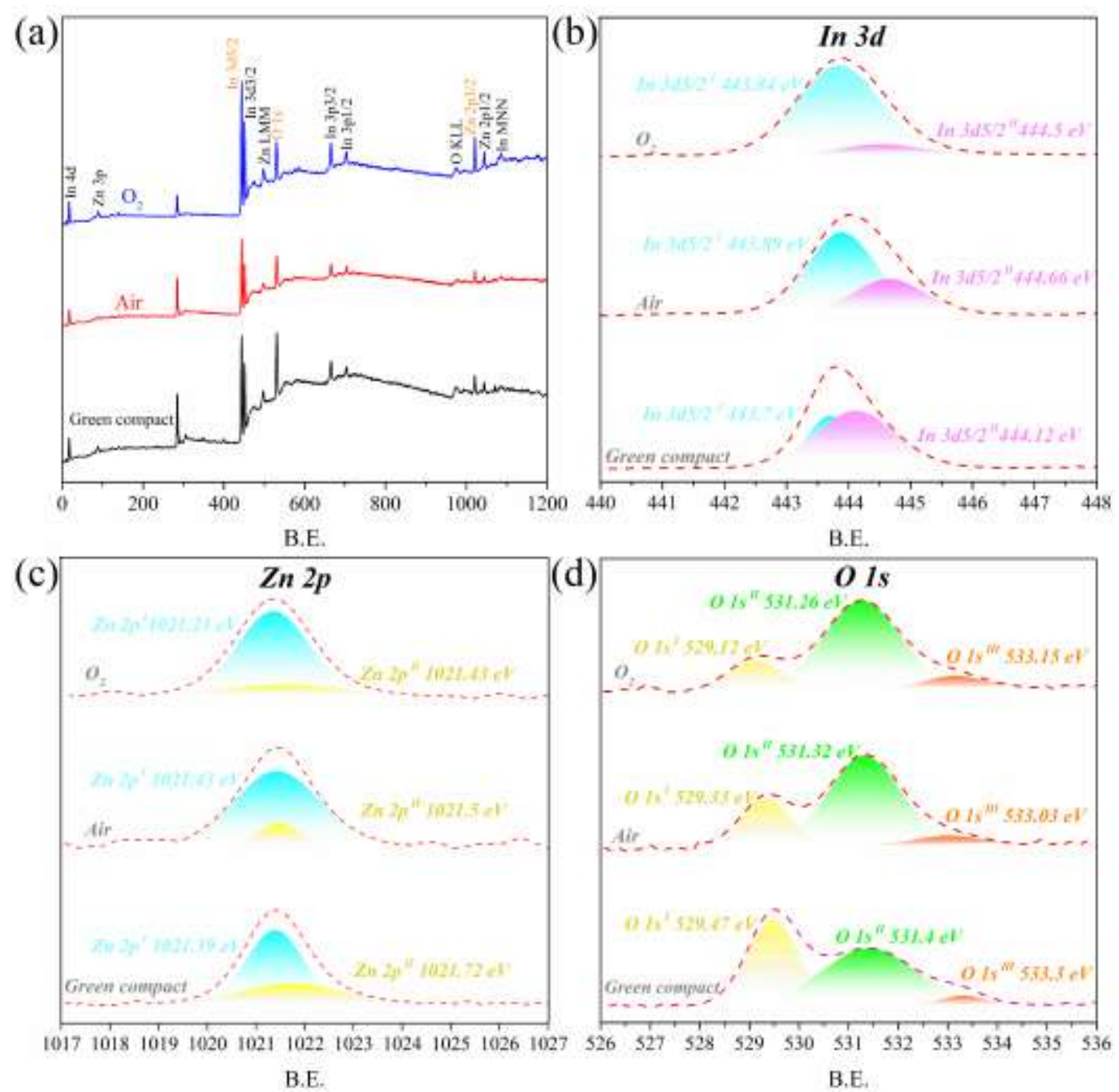

Fig. 12. XPS patterns of IZO ceramics sintered in $\mathrm{O}_{2}$ and air atmosphere: (a) In 3d, (b) $\mathrm{Zn} 2 \mathrm{p}$, (c) O $1 \mathrm{~s}$.

Table 2. Elemental chemical state content of IZO ceramics.

\begin{tabular}{|c|c|c|c|c|c|c|c|}
\hline Atmosphere & $\operatorname{In} 3 d_{5 / 2}{ }^{I}(\%)$ & ${\operatorname{In} 3 d_{5 / 2}}^{\mathrm{III}}(\%)$ & $\mathrm{Zn} 2 \mathrm{p}^{\mathrm{I}}(\%)$ & $\mathrm{Zn} 2 \mathrm{p}^{\mathrm{II}}(\%)$ & O1s ${ }^{\mathrm{I}}(\%)$ & $\mathrm{O} 1 \mathrm{~s}^{\mathrm{II}}(\%)$ & $\mathrm{O} 1 \mathrm{~s}^{\mathrm{III}}(\%)$ \\
\hline $\mathrm{O}_{2}$ & 89.58 & 10.42 & 78.45 & 21.55 & 19.06 & 72.66 & 8.28 \\
\hline Air & 68.87 & 31.13 & 86.43 & 13.57 & 24.96 & 67.35 & 7.69 \\
\hline Green compact & 31.11 & 68.89 & 65.92 & 34.08 & 43.45 & 52.52 & 4.03 \\
\hline
\end{tabular}

To investigate the solid solution rule of doped element $\mathrm{Zn}$ atom in IZO targets with sintering temperature, the samples were held at $800^{\circ} \mathrm{C}, 1000^{\circ} \mathrm{C}, 1200^{\circ} \mathrm{C}, 1400^{\circ} \mathrm{C}$ for $20 \mathrm{~h}$, and then the phase composition was analyzed by XRD. According to Fig. 13, the IZO compacts sintered at $800^{\circ} \mathrm{C}$ still consist of $\mathrm{ZnO}$ and $\mathrm{In}_{2} \mathrm{O}_{3}$ phase, and as the sintering temperature increases, part of the $\mathrm{ZnO}$ dissolves into the lattice of $\operatorname{In}_{2} \mathrm{O}_{3}$, while the remaining reacts with $\mathrm{In}_{2} \mathrm{O}_{3}$ to form a second phase $\left(\mathrm{Zn}_{3} \mathrm{In}_{2} \mathrm{O}_{6}\right)$. It was reported by Toshihiro Moriga[25], the IZO compacts have a phase evolution process as shown in the following equation when the sintering temperature varies from $1100^{\circ} \mathrm{C}$ to $1400^{\circ} \mathrm{C}: \mathrm{kZnO}+\mathrm{In}_{2} \mathrm{O}_{3} \rightarrow \mathrm{Zn}_{\mathrm{k}} \mathrm{In}_{2} \mathrm{O}_{\mathrm{k}+3}$. Moreover, $\mathrm{Zn}_{3} \mathrm{In}_{2} \mathrm{O}_{6}(\mathrm{k}=3)$ can exist stably above $1270^{\circ} \mathrm{C}$, which is consistent with the experimental results. A careful observation at the diffraction angle $\left(2 \theta \approx 30^{\circ}\right)$ reveals there is a small angle shift of the main peak to the left, 
especially the IZO ceramic sintered at $1400^{\circ} \mathrm{C}$ (from 800 to $1400^{\circ} \mathrm{C}, 2 \theta$ corresponds to $30.554^{\circ}$, $30.541^{\circ}, 30.524^{\circ}, 30.415^{\circ}$ ). According to the Bragg equation, a leftward shift of the peak implies a larger crystalline surface spacing and thus a larger lattice parameter. However, the ionic radius of $\mathrm{Zn}^{2+}(0.74 \AA, \mathrm{CN}=6)$ is smaller than that of $\operatorname{In}^{3+}(0.8 \AA, \mathrm{CN}=6)$, the doping of $\mathrm{Zn}^{2+}$ was supposed to reduce the lattice parameters of $\operatorname{In}_{2} \mathrm{O}_{3}$. A reasonable explanation for this phenomenon is the predominance of the interstitial solid solution type of $\mathrm{Zn}^{2+}$, rather than substitutional[26]. The interstitial solid solution type of $\mathrm{Zn}^{2+}$ can provide four electrons (Eq.12), which is prospective to increase carrier concentration and conductivity.

$$
2 \mathrm{ZnO} \stackrel{\mathrm{In}_{2} \mathrm{O}_{3}}{\longrightarrow} 2 \mathrm{Zn}_{i}^{\mathrm{g}}+2 \mathrm{O}_{0}^{X}+4 \mathrm{e}^{\prime}
$$

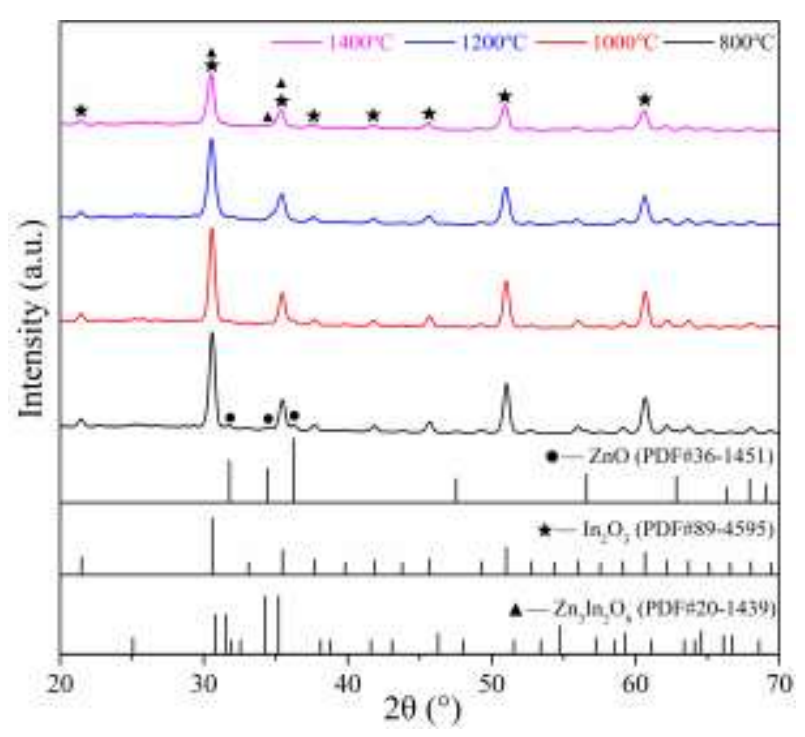

Fig. 13. XRD patterns of IZO ceramics sintered at different temperatures.

Fig.14 depicts the distribution of elements in IZO ceramics and the atomic ratio of phase composition. The apparent color of the physical phase in IZO ceramics is distinguished, with the dark area being the secondary phase $\mathrm{Zn}_{3} \mathrm{In}_{2} \mathrm{O}_{6}$ and the light area II being the primary phase $\mathrm{In}_{2} \mathrm{O}_{3}$. The elemental ratio of the secondary phase is $\mathrm{Zn}$ : $\mathrm{In}: \mathrm{O}=2.92: 2.05: 6$, and the value is close to 3:2:6 $\left(\mathrm{Zn}_{3} \operatorname{In}_{2} \mathrm{O}_{6}\right)$. In Fig. 13(a-II), 0.92 at.\% $\mathrm{Zn}$ dissolves into the cell of $\operatorname{In}_{2} \mathrm{O}_{3}$, causing lattice distortion. Meanwhile, the graph of EPMA can well reflect the uniform distribution of elements. 

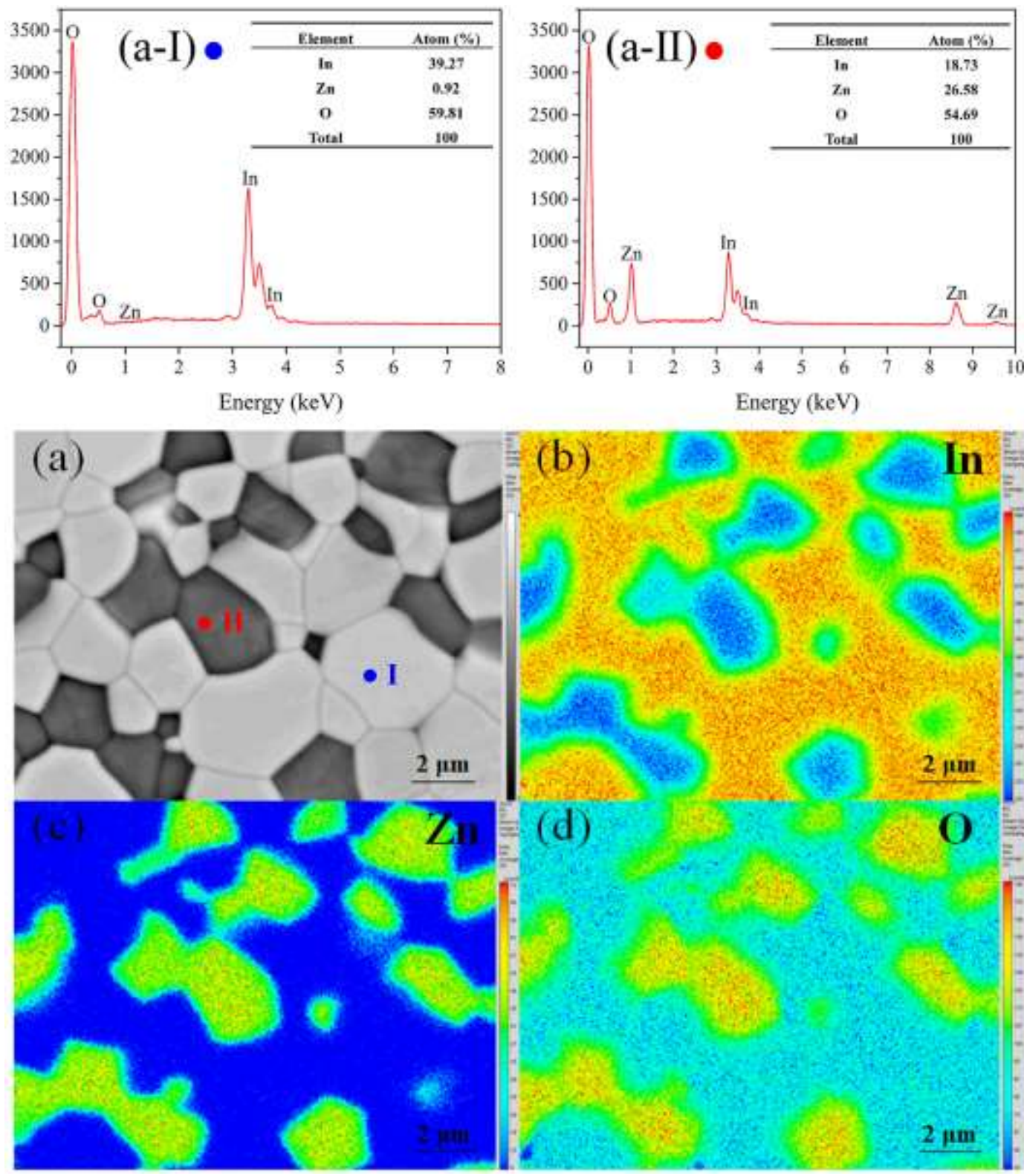

Fig. 14. Elemental distribution and content of IZO ceramics.

\section{Conclusions}

The IZO slurry with $75 \mathrm{wt} . \%$ solid content was prepared by the wet ball milling technology. It was found that the nanoparticle distribution D50 was $365 \mathrm{~nm}$ at a ball milling time of $32 \mathrm{~h}$. The IZO slurry had low viscosity (about $45 \mathrm{mPa} \cdot \mathrm{s}$ from $20 \mathrm{~s}^{-1}$ to $80 \mathrm{~s}^{-1}$ ) and low shear stress ( $2.3 \mathrm{~Pa}$ at $40 \mathrm{~s}^{-1}$ ), which was suitable for the preparation of green IZO compacts. The MSC and Brook dynamic models were constructed by combining with the densification behavior of the green IZO compacts and the apparent activation energy can be calculated as $580 \mathrm{~kJ} / \mathrm{mol}$, and grain growth activation energy is $690 \mathrm{~kJ} / \mathrm{mol}$. The grain size of IZO ceramics sintered by the TSS method can be controlled under the range of 3-6 $\mu \mathrm{m}$, where the optimal resistivity is 1.5 $\mathrm{m} \Omega \cdot \mathrm{cm}$ under the TSS 6 . The results of XPS illustrated that the IZO ceramics sintered in an oxygen atmosphere could increase the concentration of oxygen vacancies, thereby enhancing electrical properties. XRD analysis and EPMA tests showed that IZO ceramics are composed 
of $\mathrm{In}_{2} \mathrm{O}_{3}$ and $\mathrm{Zn}_{3} \mathrm{In}_{2} \mathrm{O}_{6}$, and both phases are uniformly distributed.

\section{References}

[1] Park WT, Son I, Park HW, et al. Facile routes to improve performance of solution-processed amorphous metal oxide thin film transistors by water vapor annealing. ACS Appl Mater Interfaces 2015, 7:13289-94.

[2] Jung SW, Chae SS, Park JH, et al. Microscale soft patterning for solution processable metal oxide thin film transistors. ACS Appl Mater Interfaces 2016, 8:7205-11.

[3] Tsai D-C, Chang Z-C, Kuo B-H. Thickness dependence of the structural, electrical, and optical properties of amorphous indium zinc oxide thin films. J Alloys Compd 2018, 743:603-9.

[4] Yang Z, Yang J, Meng T, Qu M, Zhang Q. Influence of channel layer thickness on the stability of amorphous indium zinc oxide thin film transistors. Materials Letters 2016, 166:46-50.

[5] Zhao X, Li J, Yang Y, et al. Low indium content In-Zn-O system towards transparent conductive films: structure, properties and comparison with AZO and GZO. Journal of Materials Science: Materials in Electronics 2017, 28:13297-302.

[6] Leong WL, Ren Y, Seng HL, Huang Z, Chiam SY, Dodabalapur A. Efficient polymer solar cells enabled by low temperature processed ternary metal oxide as electron transport interlayer with large stoichiometry window. ACS Appl Mater Interfaces 2015, 7:11099-106.

[7] Kumar N, Wilkinson TM, Packard CE, Kumar M. Design of low surface roughness-low residual stress-high optoelectronic merit a-IZO thin films for flexible OLEDs. Journal of Applied Physics 2016, 119:2253031-9.

[8] Chen J-W, Hu Y-F, Chen Z-J, et al. A low-power gate driver integrated by IZO-TFTs employing single negative power source. Semiconductor Science and Technology 2018, 33:065006-11.

[9] Shan F, Kim SJ. Effect of In/Zn ratios on resistive switching behavior of $\mathrm{IZO} / \mathrm{TiO}_{2}$ thin Film Devices. physica status solidi (a) 2019, 216:1900018-23.

[10] Mallika AN, Reddy AR, Reddy KV. Annealing effects on the structural and optical properties of ZnO nanoparticles with PVA and CA as chelating agents. Journal of Advanced Ceramics 2015, 4:123-9.

[11] Lim, LC, Wong PM. Microstructural evolution during sintering of near-monosized agglomerate-free submicron alumina powder compacts. Acta Materialia 2000, 48:2263-75.

[12] Hirata Y, Tanaka Y. Pressure filtration model of ceramic nanoparticles. Journal of the American Ceramic Society 2008, 91:819-24.

[13] Koichiro Matsushima YH, Naoki Matsunaga, Sameshima S. Pressure filtration of alumina suspensions under alternating current field. Colloids and Surfaces A: Physicochemical and Engineering Aspects 2010, 364:138-44.

[14] Li X, Liu C, Sun B, et al. Refined grain size of ITO ceramic targets prepared by pressure slip casting and two-step sintering. Journal of the European Ceramic Society 2021, 41:3501-11.

[15] Su H, Johnson DL. Master sintering curve: A practical approach to sintering. J Am Ceram Soc 1996, 79:3211-7.

[16] Pouchly V, Maca K. Master sintering curve: A practical approach to its construction. Science of Sintering 2010, 42:25-32.

[17] Mei F, Yuan T, Li R, Qin K. Effects of sintering processes on second-phase grain morphology of ITO ceramics and grain growth. Journal of Materials Science: Materials in Electronics 2017, 28:159966007.

[18] Chaim R, Shlayer A, Estournes C. Densification of nanocrystalline $\mathrm{Y}_{2} \mathrm{O}_{3}$ ceramic powder by spark 
plasma sintering. Journal of the European Ceramic Society 2009, 29:91-8.

[19] Chen IW, Wang XH. Sintering dense nanocrystalline ceramics without final-stage grain growth. Nature 2000, 404:168-71.

[20] Mei F, Yuan T, Li R, et al. Effects of element chemical states and grain orientation growth of ITO targets on photoelectric properties of the film. Ceramics International 2017, 43:14732-41.

[21] Chen J, Wang L, Su X. InGaZnO thin films grown by pulsed laser deposition. Vacuum 2012, 86:1313-7.

[22] Chirakkara S, Nanda KK, Krupanidhi SB. Pulsed laser deposited ZnO:In as transparent conducting oxide. Thin Solid Films 2011, 519:3647-52.

[23] Kuankuan Lu , Rihui Yao, Yiping Wang, Ning H. Effects of praseodymium doping on the electrical properties and aging effect of InZnO thin-film transistor. Journal of Materials Science 2019, 54:1477886.

[24] Gu F, Li C, Han D, Wang Z. Manipulating the defect structure (VO) of $\operatorname{In}_{2} \mathrm{O}_{3}$ nanoparticles for enhancement of formaldehyde detection. ACS Appl Mater Interfaces 2018, 10:933-42.

[25] Moriga T. Phase relationships and physical properties of homologous compounds in the zinc oxideindium oxide system. Journal of the American Ceramic Society 1998, 81:1310-16.

[26] Park D. Effect of $\mathrm{ZnO}$ addition in $\mathrm{In}_{2} \mathrm{O}_{3}$ ceramics: defect chemistry and sintering behavior. Solid State Ionics 2004, 172:431-4. 